\title{
LIFESTYLE AND PSYCHOSOCIAL FACTORS IN MUSICIANS
}

\author{
SEBASTIAN NEDELCUT ${ }^{1}$, DANIEL-CORNELIU LEUCUTA ${ }^{2}$, \\ DAN LUCIAN DUMITRASCU ${ }^{1}$
}

\author{
12nd Medical Department, Iuliu Hatieganu University of Medicine and Pharmacy, \\ Cluj-Napoca, Romania \\ ${ }^{2}$ Medical Informatics and Biostatistics Department, Iuliu Hatieganu University of \\ Medicine and Pharmacy, Cluj-Napoca, Romania
}

\begin{abstract}
Background and aim. Musicians face professional challenges that may lead them to adopt unhealthy lifestyles. They also may present performance-related anxiety. We investigated anxiety and lifestyle patterns in musicians, both professional and trainees.

Methods. A prospective controlled protocol was developed. Musicians (employed or students) and matched controls (also employed and students) were surveyed with several questionnaires on lifestyle and some psychological factors: anxiety and music performance anxiety.

Results. General anxiety and music performance anxiety are higher in music students compared with trained musicians. Musicians have also higher anxiety scores than their matched controls. Soloists have higher scores of anxiety, also percussion and keyboard students. Musicians smoke less than controls, but sleep also less, a factor perceived as an index for stress. BMI was also higher in musicians.

Conclusions. Performing music is associated with anxiety levels that are higher than in control population. Trainees have higher scores than the employed musicians.
\end{abstract}

Keywords: anxiety, music, lifestyle

\section{Introduction}

Musicians may be at increased risk to develop unhealthy lifestyles, and even a variety of health problems, due to the stress, anxiety, and the physical efforts they have to carry out.

It is important to acknowledge the anxiety, lifestyle problems and health issues that are more common to musicians in order to modify the education of future and present musicians, in an attempt to protect them from these problems.

There are few studies assessing lifestyles in musicians and especially comparing those who are only student musicians with those already employed, accomplished musicians.

The aim of the study was to assess differences between studying and employed musicians regarding lifestyle, anxiety levels, as well as to compare them to corresponding non musicians controls.

Manuscript received: 03.12.2017

Accepted: 05.01.2018

Address for correspondence: dleucuta@umfcluj.ro

\section{Material and methods \\ Protocol}

A total of 580 subjects responded, in a cross-sectional survey, to several questionnaires regarding demographic characteristics, anxiety, lifestyle including sleep patterns.

\section{Subjects and selection criteria}

The inclusion criteria were: musicians in Music Academies (subgroups of: singers, lyrical artists overall, keyboards and percussion, string, blowers), and corresponding controls. The controls were students at two faculties (chemistry and psychology), and subjects employed in different institutions and companies. Overall we created four groups: studying musicians and their corresponding studying controls, and employed musicians and their employed controls.

Exclusion criteria were: any documented organic gastrointestinal disorders: esophagitis; chronic gastritis, gastro/duodenal ulcer, gastric cancer; organic intestinal diseases, and systemic diseases (e.g. diabetes); and treatments that can modify gastrointestinal symptomatology.

Questionnaires

For assessing anxiety levels we used two validated 
questionnaires: the Zung Self-rating Anxiety Scale (SAS - for all the subjects [1] and the Music Performance Anxiety Inventory for Adolescents (MPAI-A-only for the musicians) [2].

\section{Statistical analysis}

Categorical data were presented as counts and percentages, and tests of associations between two qualitative variables were carried out with $\mathrm{Chi}$ squared test, and Fisher exact test. Continuous data was presented as median and interquartile ranges for data with skewed distributions, and we used the Wilcoxon rank-sum test for comparing such data between two groups or the KruskalWallis test for comparing such data between more than two groups (followed by non parametric post hoc corrections). For multiple testing we used also the Bonferroni correction.

For all statistical tests we used an alpha level of significance of 0.05 , and the two tailed $p$ value.

All statistical analyses were computed with the $\mathrm{R}$ environment for statistical computing and graphics, version 3.2.1 [3].

\section{Ethical issues}

This study was approved by the local ethical committee; informed consent was obtained for each participant.

\section{Results}

The final analysis set comprised 580 subjects -
$339(58.45 \%)$ musicians and $241(41.55 \%)$ controls. In the musicians group $162(47.79 \%)$ were singers and 177 (52.21\%) were instrumentalists. There were $136(40.12 \%)$ employed musicians and $203(59.88 \%)$ students. In detail the musicians were: soloists: $36(10.62 \%)$, ensemble lyrical artists (choristers): 126 (37.17\%), keyboard and percussion: 55 (16.22\%), strings: 79 (23.3\%),brass: 43 (12.68\%).

From the educational point of view there were two musician groups in the study: the employed musicians (136 $-40 \%)$ and the studying musicians $(203-60 \%)$, as well as two control groups: employed controls $(153-63.49 \%)$ and studying controls (36.51\%).

\section{Characteristics of the responders}

The employed musicians had statistically significant higher body mass index than studying musicians (except for soloists and brass players), with about $2 \mathrm{~kg} / \mathrm{sq} . \mathrm{m}$, the highest values being seen in choristers, keyboards and percussion performs, and string players. The body mass index was overall higher in the musician group compared to the control group ( $22.66 \mathrm{vs} 21.37 \mathrm{~kg} / \mathrm{sq} . \mathrm{m}$ - medians, $\mathrm{p}<0.001)$. The age and the education levels of the employed responders were higher than in the studying responders. The studying control group included more females than the employed group, but there were no statistically significant differences between studying and employed musicians in any musicians' group. More detailed characteristics can be found in Table I.

Table I. Demographic characteristics of the studying and employed musicians and controls.

\begin{tabular}{|c|c|c|c|c|c|c|c|}
\hline $\begin{array}{l}\text { Studying vs. employed } \\
\text { musicians }\end{array}$ & \begin{tabular}{|l}
$\begin{array}{l}\text { Soloists } \\
(\mathrm{n}=18 / 18)\end{array}$ \\
\end{tabular} & \begin{tabular}{|l|} 
Choristers \\
$(\mathrm{n}=72 / 74)$
\end{tabular} & $\begin{array}{l}\text { Keyboards and } \\
\text { percussion }(\mathrm{n}=34 / 21)\end{array}$ & \begin{tabular}{|l|} 
String \\
$(\mathrm{n}=51 / 28)$
\end{tabular} & \begin{tabular}{|l|} 
Brass \\
$(\mathrm{n}=28 / 15)$
\end{tabular} & \begin{tabular}{|l} 
Control \\
$(\mathrm{n}=153 / 88)$
\end{tabular} & P-value ** \\
\hline $\begin{array}{l}\text { Studying: Age (years), } \\
\text { median (IQR) }\end{array}$ & $21(20-22)$ & $22(20-23)$ & $20.5(20-21.75)$ & $21(20-21.5)$ & $20.5(20-22)$ & $21(20-22)$ & 0.003 \\
\hline $\begin{array}{l}\text { Employed Age (years), } \\
\text { median (IQR) }\end{array}$ & $36(30.25-44)$ & $37(30.25-40.75)$ & $35(31-41)$ & $38.5(32-43)$ & $35(32-38.5)$ & $30(24-36.25)$ & $<0.001$ \\
\hline p-value * & $<0.001 /<0.001$ & $<0.001 /<0.001$ & $<0.001 /<0.001$ & $<0.001 /<0.001$ & $<0.001 /<0.001$ & $<0.001 /<0.001$ & \\
\hline $\begin{array}{l}\text { Studying: } \\
\text { Female, n (\%) }\end{array}$ & $13(72.22)$ & $39(54.17)$ & $23(67.65)$ & $24(47.06)$ & $14(50)$ & $134(87.8)$ & $<0.001$ \\
\hline $\begin{array}{l}\text { Employed: } \\
\text { Female, } \mathrm{n}(\%) \\
\end{array}$ & $10(55.56)$ & $28(51.85)$ & $10(47.62)$ & $17(60.71)$ & $8(53.33)$ & $50(56.82)$ & 0.946 \\
\hline p-value * & $0.13 / 0.78$ & $0.823 / 1$ & $0.343 / 1$ & $0.583 / 1$ & $0.366 / 1$ & $<0.001$ & \\
\hline $\begin{array}{l}\text { Studying: Educational } \\
\text { levels, n (\%) } \\
\text { low: } \\
\text { middle: } \\
\text { high: }\end{array}$ & \begin{tabular}{|l}
$0(0)$ \\
$17(94.44)$ \\
$1(5.56)$ \\
\end{tabular} & $\begin{array}{l}0(0) \\
59(81.94) \\
13(18.06)\end{array}$ & $\begin{array}{l}0(0) \\
33(97.06) \\
1(2.94)\end{array}$ & $\begin{array}{l}0(0) \\
50(98.04) \\
1(1.96)\end{array}$ & $\begin{array}{l}0(0) \\
25(89.29) \\
3(10.71) \\
\end{array}$ & $\begin{array}{l}0(0) \\
128(84.21) \\
24(15.79)\end{array}$ & 0.016 \\
\hline $\begin{array}{l}\text { Employed: Educational } \\
\text { levels, } \mathrm{nr}(\%) \\
\text { low: } \\
\text { middle: } \\
\text { high: }\end{array}$ & \begin{tabular}{|l}
$0(0)$ \\
$4(22.22)$ \\
$14(77.78)$
\end{tabular} & $\begin{array}{l}0(0) \\
8(14.81) \\
46(85.19)\end{array}$ & $\begin{array}{l}0(0) \\
1(4.76) \\
20(95.24)\end{array}$ & $\begin{array}{l}0(0) \\
0(0) \\
28(100)\end{array}$ & $\begin{array}{l}0(0) \\
0(0) \\
15(100)\end{array}$ & $\begin{array}{l}10(11.36) \\
30(34.09) \\
48(54.55)\end{array}$ & $<0.001$ \\
\hline p-value * & $<0.001 /<0.001$ & $<0.001 /<0.001$ & $<0.001 /<0.001$ & $<0.001 /<0.001$ & $<0.001 /<0.001$ & $<0.001 /<0.001$ & \\
\hline $\begin{array}{l}\text { Studying: BMI (kg/ } \\
\text { m2), median (IQR) }\end{array}$ & $22.31(19.75-24.93)$ & $21.63(20.27-24.77)$ & $22.34(19.66-25.3)$ & $21.09(19.43-23.68)$ & $20.67(19.6-22.24)$ & $20.7(19.23-22.86)$ & 0.031 \\
\hline $\begin{array}{l}\text { Employed: BM } \\
(\mathrm{kg} / \mathrm{m} 2), \text { median (IQR) }\end{array}$ & $23.14(22.11-24.8)$ & $24.05(21.48-26.9)$ & $24.8(22.02-27.47)$ & $24.37(21.68-27.14)$ & $23.34(2.36-24.9)$ & $22.78(20.2-25.7)$ & .492 \\
\hline p-value $*$ & \begin{tabular}{|l|}
$0.195 / 0.980$ \\
\end{tabular} & $0.007 / 0.042$ & $0.004 / 0.024$ & $<0.001 /<0.001$ & $0.025 / 0.150$ & $<0.001 /<0.001$ & \\
\hline
\end{tabular}

* - uncorrected/Bonferroni corrected p-values for the comparisons between studying and employed groups within each musician type subgroups; ** p-values for the comparisons between all musician types and their corresponding control group within each education groups: studying and employed ones; BMI - body mass index (weight in $\mathrm{kg}$ / height in sq.m), IQR - interquartile range. 


\section{Anxiety levels}

When comparing overall the studying to the employed musicians we observed statistically significant differences for anxiety levels measured with both Zung SAS score [36 (30 - 43) vs. 28 (19.5 - 36) - median (IQR), $\mathrm{p}<0.001]$ and with MPAI-A score [33 (18 - 42.5) vs. 22 (13 - 35) - median (IQR), $\mathrm{p}<0.001]$, both showing higher anxiety in studying musicians. When using the Zung SAS score, looking into each musician group, statistically significant differences were observed with higher anxiety scores for studying compared to employed musicians (except for soloists, keyboards and percussion who had higher observed scores in the employed musicians compared to studying ones - but without reaching statistical significance). With the MPAI-A anxiety score, looking into each musician group, we found higher anxiety scores for studying compared to employed musicians (except for soloists who had higher observed scores in the employed musicians compared to studying ones).- but the differences were statistically significant only for strings and brass.

When comparing Zung SAS anxiety scores between all employed musicians to employed controls, or between all studying musicians to studying controls, no statistically significant differences were observed.

The comparisons between each musicians group and their corresponding control group within the studying or employed groups we found some statistically significant differences. The highest Zung SAS anxiety scores were observed in the soloists, keyboard and percussion groups, for both studying and employed groups. The highest MPAI-A anxiety scores were observed for keyboard and percussion groups within the studying musicians, and for the soloist group within the employed musicians. A detailed presentation of anxiety scores is in Table II.

\section{Lifestyle patterns}

Overall, the studying musicians eat less on the run [58 (17.68)] compared to employed ones [52 (39.39\%), $\mathrm{p}<0.001]$, have more meals per day with their family [76 (23.1) vs. 26 (12.56), $p=0.002]$, sleep less than 7 hours/day less frequently [53 (15.82) vs. 68 (31.19), $\mathrm{p}<0.001]$, and have more sleep problems - medium to very important [169 (47.47) vs. 68 (30.36), $\mathrm{p}<0.001]$. But, when looking into each musician group no statistically significant differences were observed between studying and employed musicians, after applying the correction for multiple testing, except for eating on the run, and smoking (that was less frequent in the employed musicians).

When comparing overall employed musicians to employed musicians' controls we observed less smoking in the employed musicians [26 (19.26) vs. 23 (36.51), $\mathrm{p}=0.009]$, more ease in expressing emotions in the employed musicians [98 (72.06) vs. 48 (54.55), $\mathrm{p}=0.007$ ], and more sleeping problems - medium to very important [48 (35.29) vs. 20 (22.73), $\mathrm{p}=0.046$ ]. When comparing overall studying musicians to studying musicians' controls we observed more sleeping problems - medium to very important [111 (54.68) vs. 58 (37.91), $\mathrm{p}=0.002]$.

The comparisons between each musician's group and their corresponding control group within the studying or employed groups identified some statistically significant differences. Thus, within the employed respondents the controls smoked the most, followed by soloists and brass. The most sleeping problems - medium to very important were observed in soloists, keyboard and percussion, for the studying respondents and employed ones. Regarding alcoholic drinks in the studying group, the strings, followed by keyboard and percussion, admitted to them more frequently. Lifestyle findings are presented in Table III.

Table II. Anxiety levels of the studying and employed musicians and controls.

\begin{tabular}{|c|c|c|c|c|c|c|c|}
\hline $\begin{array}{l}\text { Studying vs. employed } \\
\text { musicians }\end{array}$ & \begin{tabular}{|l} 
soloists \\
$(\mathrm{n}=18)$
\end{tabular} & $\begin{array}{l}\text { chorists } \\
(\mathrm{n}=54)\end{array}$ & $\begin{array}{l}\text { keyboard } \\
(\mathrm{n}=21)\end{array}$ & $\begin{array}{l}\text { strings } \\
(\mathrm{n}=28)\end{array}$ & $\begin{array}{l}\text { brass } \\
(\mathrm{n}=15)\end{array}$ & $\begin{array}{l}\text { control } \\
(\mathrm{n}=88)\end{array}$ & P-value ** \\
\hline $\begin{array}{l}\text { Studying: Zung SAS } \\
\text { score, median (IQR) }\end{array}$ & $42(31.75-52.5)$ & $32(19.5-39.5)$ & $45.5(38.25-49.75)$ & $35(30-43)$ & $32(28-35)$ & $37(31-43)$ & $<0.001$ \\
\hline $\begin{array}{l}\text { Employed: Zung SAS } \\
\text { score, median (IQR) }\end{array}$ & $43.5(30-51.5)$ & $20(9.25-34.75)$ & $46(27-49)$ & $26(17.75-29)$ & $23(8.5-25)$ & $30(24-34.25)$ & $<0.001$ \\
\hline p-value $*$ & $0.32 / 1$ & $0.006 / 0.036$ & $0.139 / 0.734$ & $<0.001 /<0.001$ & $0.001 / 0.006$ & $<0.001 /<0.001$ & \\
\hline $\begin{array}{l}\text { Studying: MPAI-A anxiety } \\
\text { score, median (IQR) }\end{array}$ & $35(22.25-40)$ & $25(15-34.25)$ & $41(33.5-50.5)$ & $32(19.5-42.5)$ & $35.5(21.75-44.25)$ & - & $<0.001$ \\
\hline $\begin{array}{l}\text { Employed: MPAI-A anxiety } \\
\text { score, median (IQR) }\end{array}$ & $35(25.75-41.75)$ & $16.5(13-32)$ & $31(22-41)$ & $20.5(9-31.25)$ & $16(9.5-26)$ & - & $<0.001$ \\
\hline p-value $*$ & $0.341 / 1$ & $0.232 / 0.86$ & $0.016 / 0.080$ & $0.002 / 0.010$ & $0.001 / 0.005$ & - & \\
\hline
\end{tabular}


Table III. Lifestyle characteristics of the studying and employed musicians and controls.

\begin{tabular}{|c|c|c|c|c|c|c|c|}
\hline Studying vs. employed musicians & \begin{tabular}{|l} 
Soloists? \\
$(\mathrm{n}=18 / 18)$
\end{tabular} & $\begin{array}{l}\text { choristers } \\
(\mathrm{n}=72 / 74)\end{array}$ & $\begin{array}{l}\text { Keyboard and } \\
\text { percussion } \\
(\mathrm{n}=34 / 21)\end{array}$ & $\begin{array}{l}\text { Strings } \\
(\mathrm{n}=51 / 28)\end{array}$ & $\begin{array}{l}\text { Brass } \\
(\mathrm{n}=28 / 15)\end{array}$ & $\begin{array}{l}\text { control } \\
(\mathrm{n}=153 / 88)\end{array}$ & P-value ** \\
\hline Studying: No breakfast, n (\%) & $1(9.09)$ & $2(3.85)$ & $4(11.76)$ & $5(9.8)$ & $2(7.14)$ & $15(9.8)$ & 0.752 \\
\hline Employed: No breakfast, n (\%) & $2(11.11)$ & $5(9.26)$ & $1(5)$ & $2(8.33)$ & $2(15.38)$ & $6(8.96)$ & 0.937 \\
\hline p-value * & $0.339 / 1$ & $0.184 / 1$ & $1 / 1$ & $0.064 / 0.512$ & $0.332 / 1$ & $0.728 / 1$ & \\
\hline Studying: Eating on the run, $\mathrm{n}(\%)$ & $2(18.18)$ & $9(17.65)$ & $3(8.82)$ & $7(13.73)$ & $4(14.29)$ & $33(21.57)$ & 0.522 \\
\hline Employed: Eating on the run, $\mathrm{n}(\%)$ & $7(38.89)$ & $20(37.74)$ & $8(40)$ & $12(44.44)$ & $5(35.71)$ & $18(26.87)$ & 0.621 \\
\hline p-value $*$ & $0.151 / 0.706$ & $0.003 / 0.018$ & 0.046 & $<0.001 /<0.001$ & $0.222 / 1$ & $0.082 / 0492$ & \\
\hline Studying: No meals with family/day, n (\%) & $2(18.18)$ & $13(25)$ & $11(32.35)$ & $16(31.37)$ & $6(21.43)$ & $28(18.3)$ & 0.317 \\
\hline Employed: No meals with family/day, n (\%) & $2(11.11)$ & $9(16.67)$ & $3(15)$ & $1(3.57)$ & $1(6.67)$ & $10(13.89)$ & 0.63 \\
\hline p-value * & $1 / 1$ & $0.313 / 1$ & $0.052 / 0.312$ & $0.041 / 0.246$ & $0.134 / 0.794$ & $0.452 / 1$ & \\
\hline Studying: Smoking, n (\%) & $1(10)$ & $16(33.33)$ & $12(35.29)$ & $19(37.25)$ & $8(28.57)$ & $48(31.37)$ & 0.661 \\
\hline Employed: Smoking, n (\%) & $6(33.33)$ & $7(12.96)$ & $6(30)$ & $2(7.14)$ & $5(33.33)$ & $23(36.51)$ & 0.006 \\
\hline p-value $*$ & $0.461 / 1$ & $0.003 / 0.018$ & $0.555 / 1$ & $0.005 / 0.030$ & $0.794 / 1$ & $0.554 / 1$ & \\
\hline Studying: Sleeping <=7 hours/day, n (\%) & $2(16.67)$ & $8(14.04)$ & $5(14.71)$ & $9(17.65)$ & $4(14.29)$ & $25(16.34)$ & 0.996 \\
\hline Employed: Sleeping <=7 hours/day, n (\%) & $7(38.89)$ & $13(24.07)$ & $9(45)$ & $9(32.14)$ & $3(20)$ & $27(32.53)$ & 0.479 \\
\hline p-value $*$ & $0.075 / 0.450$ & $0.028 / 0.168$ & $0.026 / 0.156$ & $0.379 / 1$ & $0.181 / 1$ & $0.001 / 0.003$ & \\
\hline Studying: No exercise, $\mathrm{n}(\%)$ & $6(33.33)$ & $7(9.72)$ & $5(14.71)$ & $5(9.8)$ & $1(3.57)$ & $15(9.8)$ & 0.078 \\
\hline Employed: No exercise, n (\%) & $2(11.11)$ & $5(9.26)$ & $3(14.29)$ & $4(14.29)$ & $1(6.67)$ & $17(19.32)$ & 0.657 \\
\hline p-value * & $0.162 / 0.972$ & $0.824 / 1$ & $1 / 1$ & $0.312 / 1$ & $1 / 1$ & $0.007 / 0.042$ & \\
\hline Studying: Expressing emotions (less easy), n (\%) & $8(44.44)$ & $22(30.56)$ & $12(35.29)$ & $28(54.9)$ & $10(35.71)$ & $58(37.91)$ & 0.145 \\
\hline Employed: Expressing emotions (less easy), n (\%) & $8(44.44)$ & $15(27.78)$ & $6(28.57)$ & $5(17.86)$ & $4(26.67)$ & $40(45.45)$ & 0.059 \\
\hline p-value * & $0.461 / 1$ & $0.69 / 1$ & $0.806 / 1$ & $0.017 / 0.102$ & $0.682 / 1$ & $0.478 / 1$ & \\
\hline $\begin{array}{l}\text { Studying: Sleep problems - medium to very } \\
\text { important, } \mathrm{n}(\%)\end{array}$ & $13(72.22)$ & $31(43.06)$ & $23(67.65)$ & $29(56.86)$ & $15(53.57)$ & $58(37.91)$ & 0.003 \\
\hline $\begin{array}{l}\text { Employed: Sleep problems - medium to very } \\
\text { important, } \mathrm{n}(\%)\end{array}$ & $9(50)$ & $14(25.93)$ & $12(57.14)$ & $8(28.57)$ & $5(33.33)$ & $20(22.73)$ & 0.02 \\
\hline p-value * & $0.202 / 1$ & $0.037 / 0.222$ & $0.806 / 1$ & $0.122 / 0.732$ & $0.722 / 1$ & $0.028 / 0.168$ & \\
\hline Studying: Alcoholic drinks, n (\%) & $5(38.46)$ & $24(41.38)$ & $14(53.85)$ & $30(69.77)$ & $12(52.17)$ & $60(42.25)$ & 0.034 \\
\hline Employed: Alcoholic drinks, n (\%) & $13(86.67)$ & $19(40.43)$ & $9(47.37)$ & $11(50)$ & $7(58.33)$ & $45(56.96)$ & 0.056 \\
\hline p-value * & $0.089 / 0.534$ & $0.567 / 1$ & $0.727 / 1$ & $0.033 / 0.198$ & $0.76 / 1$ & $0.022 / 0.132$ & \\
\hline
\end{tabular}

* - uncorrected/Bonferroni corrected p-values for the comparisons between studying and employed groups within each musician type subgroups; ** $\mathrm{p}$-values for the comparisons between all musician types and their corresponding control group within each education groups: studying and employed ones.

\section{Discussion}

The present paper proposed to assess lifestyle, anxiety levels between different levels of experience in musicians (students of music and professional employed performers), and non musicians.

The employed musicians had higher body weight than the students, and higher body weight compared to controls. This indicates a weight problem in musicians that has to be addressed, especially in the employed ones.

The employed musicians had overall lower anxiety compared to studying ones, but there were no differences between musicians and controls - suggesting the experience helping to reduce this anxiety probably in many domains of work. We found that soloists had higher anxiety in the employed group compared to the studying group, without reaching statistical significance. Further studies should assess this observation and if it is proved to be real, this category should benefit from specific help to address this problem.

Lifestyle is unhealthy in both musician groups: bad eating habits (eating on the run, having fewer meals per day with their family) are more frequent in the employed musicians; studying musicians on the other hand had less sleep and more sleep problems. While all these bad patterns are expected, the sleeping problems are more frequent in musicians (both employed and studying), compared to controls. The most affected musicians by sleeping problems are the soloists, keyboard players and percussionists.

Our study has some limitations: A classic problem, when using questionnaires, is the reliability of the answer and the answering bias. On the other hand, our sample was large enough to prevent such errors. The respondents might also try to hide some aspects of their lifestyle that might be considered bad for their job, or inappropriate, in order to increase own social desirability. To limit this behavior we used anonymous questionnaires, but the risk might not have been completely avoided.

This is to our knowledge one of the very few studies looking on behavior of musicians compared to control groups. In a recent study, eating disorders were reported in 
musicians [4]. Our study confirms that musicians may have an unhealthy nutrition pattern, exposing them to weight challenges. It is not only the stressful lifestyle causing differences versus the general population, but also the acoustic factor itself [5].

Therefore music students need adapted training in order to be able to cope with the particularities of their professional and personal life [6].

However, music has not only deleterious effects on the performers. The music may enrich the life of many musicians, offering a degree of satisfaction that few other professions may offer [7].

Of course our paper refers to classical music, which has its own risks [8], which are considerably different from popular music, the latter being adopted by musicians who frequently live marginally and are exposed to many more risks [9].

\section{Conclusions}

Employed musicians have higher body weight, less anxiety (except for soloists), eat more frequently on the run, have less meals per day with their family, have less sleep problems, smoke less than music students. Music students show unhealthy behaviors more frequently than controls. These findings suggest the need for changes in education, lifestyle and policies in order to improve the life and health of musicians.

\section{References}

1. Zung WW. A rating instrument for anxiety disorders. Psychosomatics. 1971;12(6):371-379.

2. Osborne MS, Kenny DT. Development and validation of a music performance anxiety inventory for gifted adolescent musicians. J Anxiety Disord. 2005;19(7):725-751.

3. R Core Team. R: A Language and Environment for Statistical Computing. Vienna, Austria; 2015.

4. Kapsetaki ME, Easmon C. Eating disorders in musicians: a survey investigating self-reported eating disorders of musicians. Eat Weight Disord. 2017 Jul 14. doi: 10.1007/s40519-017-04149. [Epub ahead of print]

5. Tufts JB, Skoe E. Examining the noisy life of the college musician: weeklong noise dosimetry of music and non-music activities. Int J Audiol. 2017 Nov 24:1-8. doi: 10.1080/14992027.2017.1405289. [Epub ahead of print]

6. Araújo LS, Wasley D, Perkins R, Atkins L, Redding E, Ginsborg J, et al. Fit to Perform: An Investigation of Higher Education Music Students' Perceptions, Attitudes, and Behaviors toward Health. Front Psychol. 2017 Oct 10;8:1558. doi: 10.3389/ fpsyg.2017.01558.

7. Singh AR. What Music Means To Me. Mens Sana Monogr. 2016;14(1):229-239.

8. Sousa CM, Machado JP, Greten HJ, Coimbra D. Occupational Diseases of Professional Orchestra Musicians from Northern Portugal: A Descriptive Study. Med Probl Perform Art. 2016;31(1):8-12.

9. Kenny DT, Asher A. Life Expectancy and Cause of Death in Popular Musicians: Is the Popular Musician Lifestyle the Road to Ruin? Med Probl Perform Art. 2016;31(1):37-44. 